\title{
WHO'S IN CHARGE, AND WHO SHOULD BE: E-GOVERNMENT AND THE CHANGING ROLE OF THE PUBLIC ADMINISTRATOR
}

John Eric Uggen

\begin{abstract}
The spread of web-based software applications and the growth of the Internet have enabled a new form of interaction between citizens and government. As new technology implementarion is no longer the sole responsibility of IT departments and as public sector information systems become more complex, public administrators must adapt to the new demands imposed by these systems. In particular, public administrators will have a central role in shaping the development of electronic government, or e-government. As the variety of e-government products and services grows, industry analysts predict the number of people using e-government will grow by 1,000 percent during the next twenty years. This will require public administracors to examine current IT outsourcing practices and to nurture skill development in preparation for future trends in information systems management.
\end{abstract}

\section{Introduction}

The impact of information systems technologies can be found in almost every aspect of the modern world. In the public sector, information systems are gathering new types of information and making it available in ways that were unimaginable only a few years ago. Ordinary citizens are using Internet and online technology to schedule tree trimmings, attend virtual town meetings, pay traffic tickets, and apply for licenses and permits. In turn, public administrators can use this technology directly or indirectly-either by automating certain functions and services or by making more informed decisions about constituent needs and expectations. Increasingly, as the Internet makes its way into public service professions, citizens will grow more accustomed to utilizing an Internet site to obtain information and services, rather than traveling to a physical location.
If public sector agencies are to make the most of these new technologies, public administrators must refocus their attention on the proper integration of information systems into their organizations and learn how to manage the sweeping changes that occur after implementation. Public administrators must not only use this knowledge to effectively manage current information systems problems, but must also use it to anticipate future problems. Among the most prominent issues currently affecting public sector information systems is the management of Enterprise Resource Planning (ERP) implementations and information technology (IT) outsourcing relationships, while the management of electronic government, or egovernment, looms large in the future.

\section{The Management of ERP Implementations in the Public Sector}

No longer the exclusive domain of IT departments, contemporary information systems are growing in size and complexity, becoming enterprise wide, and encompassing every function of the organization by integrating and centralizing various enterprise functions, such as human resource management, payroll, strategic planning, accounting, and financial management.' By virtue of their complexity, information systems necessitate increasing organizational restructuring and high levels of commitment from top management and frontline employees, who require ongoing training. Given these tremendous challenges, the transition to ERP software packages has proven to be difficult, costly,

John Eric Uggen is pursuing a Master of Public Administration degree at The George Washington University. Mr. Uggen currently works for the International Public Sector Services Division of KPMG Consulting Inc. Prior to joining KPMG, he served as a Small Business Development Peace Corps Volunteer in the Republic of Moldova. Mr. Uggen recieved a Bachelor of Arts in History from Willamette University. 
and lengthy, even in the private sector. However, as demand for governmental accountability and efficiency increases, more public managers will feel pressure to convert and migrate to these applications, despite the fact that they remain largely untested in the public sector. ${ }^{2}$

Many public organizations are also turning to the Internet. What both businesses and governments are discovering is that the average citizen is growing intolerant of traveling across town or waiting in line for services. The success stories of Dell Computer and Amazon.com illustrate how consumers are demanding customized services and products in ways that only the Internet can deliver. The refinement of Internet technology has also enabled software applications to handle many of the same functions as conventional ERP applications, only adding to the functionality of the Internet. The lure for the public sector is the promise that these technologies will deliver more streamlined operations with reduced costs. However, buying and implementing these technologies is complicated and costly. In organizations undergoing complex implementations, managers must examine the relationships between the disparate organizational functions and the organization's relationship to the outside world. New technologies depend on the careful integration of organizational functions and external information from vendors and constituents in order to operate properly. For organizations unprepared to make the necessary organizational and management style changes, the costs of implementation could also prove fatal; and where the public sector is concerned, the costs of botched or otherwise unsuccessful implementations are extracted in political terms. ${ }^{3}$

One form of ERP that has received considerable scrutiny in the public administration literature is Geographic Information Systems (GIS). In brief, GIS "allow governments to capture, manage, analyze and call on land related data to solve complex planning and management problems." Furthermore, the capabilities of GIS "to integrate and sort data from separate databases on demand provide major benefits to government administrators." However, despite the overwhelming list of benefits that GIS provide, like more complex ERP systems, GIS require significant attention on behalf of the public administrator to organizational issues. According to Ventura, "successful use of GIS depends on technical choices and on the ability, capacity, and willingness of an organization to absorb and use new forms and quantities of information." Although many of these organizational issues can be addressed through training, other barriers such as the perceived costs and benefits, the organizational decisionmaking structure, and communication flow within an organization may also impede effective implementation.
Therefore, resistance to new technology is ultimately a "people problem." Ventura writes that:

fear of change, difficulty in learning or accepting new methods, struggles over authority [contribute to ineffective technology implantation]. Fear of change takes the form of bureaucratic inertia when agencies seek to maintain the status quo by fulfilling their explicit mandate as narrowly and expeditiously as possible, rather than seeking more effective ways to serve policymakers and the public. ${ }^{7}$

The consequences of insufficient attention to these problems are frequently highlighted in the media. For example, an ERP system implementation came under fire in Oakland, California when the software failed to accurately print city payroll checks. According to city officials, the blame rests on "data entry mistakes made by city employees who, though trained, were unfamiliar with the software."

Unfortunately, these disruptions are becoming more common as ERP systems gain in popularity in both the private and public sectors. In other incidents, Hershey Corporation and clothing maker Gore-Tex experienced problems with the implementations of their ERP systems that resulted in huge delays and setbacks. The reason, according to industry analysts, is that corporations greatly underestimate the degree to which they must commit resources to training, organizational change, and strong project leadership. ${ }^{9}$ In short, ERP implementations are not limited to the functions of an isolated IT department but require the full attention of the entire organization if the implementation is to be successful. Recognizing the differences between private and public sector implementations, Cats-Baril and Thompson argue that successful implementation in the public sector depends on:

(1) clear project goals, leadership, and specific responsibilities; (2) given the turnover of top level administrators and the constraints imposed by red tape, the need to convince employees to change the existing organizational processes is greater and the difficulty to implement change is increased; (3) given the incremental nature of governmental decisionmaking, the criteria to justify radical technological innovations are more stringent; and (4) given that MIS directors tend to have less authority than their private sector counterparts, the careful choosing of a project leader with both technical knowledge and po- 
litical clout is essential. ${ }^{10}$

A key facet of ERP implementation overlooked by most managers is that ERP systems decentralize traditional command and control structures. In the case of the Oakland payroll problem, regular employees found themselves entering data while not fully aware of how mistakes or shortcuts might affect the entire system, resulting in payroll problems. According to Bingi, Sharma, and Godla, "without proper training, about 30 percent to 40 percent of the frontline workers will not be able to handle the demands of the new system." " Referring to the private sector, the authors further assert that "some companies make the grave mistake of handing over the responsibility of ERP implementation to the technology department. This would risk the entire company's survival because of the ERP system's profound business applications." Yet despite these clear warnings, many public sector organizations continue to rush headlong into implementation, blind to the potential risks, without adequate strategic planning beforehand, and sufficient follow-up training afterward.

\section{The Management of IT Contracting and Outsourcing Relationships in the Public Sector}

In the National Performance Review (NPR), government agencies are informed that "private firms can perform noncore functions better, cheaper, and faster." 12 Many public administration scholars have also argued that outsourcing provides governments with an inexpensive means to access and use technological innovations. ${ }^{13}$ Through outsourcing, it is argued that organizations are "freed" from financing the large overhead start-up costs associated with implementing information systems. Organizations also need not invest heavily in personnel, facilities, or equipment, as the contractor would assume these costs. In addition, outsourcing should allow managers to concentrate more fully on core organizational activities and spare frontline staff from the burdens associated with carrying out implementation. ${ }^{14}$ The key question, however, is the effectiveness of outsourcing as more public sector organizations seek to utilize this tool to help them establish a presence online.

As the trend toward outsourcing further develops and as IT begins to play a more central role in the provision of government services, a critical element in assessing the effectiveness of the outsourcing relationship concerns the redefinition of what should be considered non-core, or "mission critical." Most agencies define mission critical functions as those that are integral to the ongoing operation of the agency.
Organizations retain control of these functions because they are unwilling to take the risks associated with interruptions in service should a breach of contract occur. ${ }^{15}$ In an online society, public sector mission critical functions will also include interacting with the public through nontraditional means such as websites or other automated information systems. But conventional wisdom does not ascribe mission critical status to the operation of information systems since they do not represent a "core competency" of most federal agencies. This argument, however, loses its saliency when we consider how important information systems have become in facilitating direct contact with, and information and service delivery to, the public. As Ferris writes:

When downsizing is occurring, organizarions are expected to protect their core functions and let the others go. But if IT is indeed the backbone of the federal government, should it be outsourced? One school of thought holds that in a society driven by information, IT is a central competency, not simply a support function. An agency that loses control of its IT or even just makes some mistakes in selecting its outsourcing contractor may be hampered. Without first-rate information systems and services, it could function less effectively and lose public support. ${ }^{16}$

There are also other considerations aside from the risks involved with outsourcing potential agency core competencies. Brown and Brudney found that as agencies increased spending on outsourcing, the associated benefits of outsourcing decreased, noting that as "management capacity is sacrificed for high levels of contracting, success in adopting and implementing an information system is often compromised."17 Therefore, contrary to the admonitions of the NPR, only a moderate level of outsourcing may be appropriate. One of the main reasons that IT outsourcing relationships fail, according to Cats-Baril and Thompson, is that although outsourcing initially made economic sense, an organization's internal capacities may not be adequate to manage the increasing complexity of the projects. In other words, it is not the outsourcing itself that fails, but the management of the IT outsourcing relationship. The findings suggest that high levels of contracting not only threaten the ability to implement and achieve positive outcomes, but outsourcing also impedes the development of requisite internal resources to manage and oversee the project successfully. ${ }^{18}$ 
An additional concern is the role of private consultants in the outsourcing process. According to Saint-Martin, consultants have had increasing influence in policy formulation during the last twenty years, and may in fact be responsible for instigating many of the New Public Management reforms seen throughout the Organization for Economic Cooperation and Development (OECD) and the United States. ${ }^{19}$ In outsourcing relationships requiring intensive consulting support, many policymakers defer to external consultants when internal management encounters a political impasse. The question before public administrators is, therefore, to what extent the administrator defers implementation decisions to those with distinct financial interests in maximizing the outsourcing relationship. If the requisite knowledge is not available or internal capacities are not developed within the organization to monitor IT outsourcing relationships, where does the authority to curtail a project reside, in the administrator or the consultant? More importantly, who has the authority to shape the way the public perceives and interacts with government online? Administrators have a particular advantage because they have the ability to coordinate the development and deployment of an e-government service whereas outsourcing agents have a limited perspective of the broader organization if they do not have knowledge of what other contractors are engaged in. Through coordination, administrators can thereby standardize the variety of services available. When requests for information or services are fulfilled by those directly responsible for meeting those needs, citizens also benefit. Yet if administrators are unwilling or technically incompetent to oversee these initiarives, the decisions as to how e-government is shaped and what it will eventually look like will be deferred to consultants whose interest is financial. This also adds an additional layer between the service provider and service recipient.

\section{Outsourcing E-Government}

Although much of the information about e-government emanates from sources with commercial interests in government, thousands of municipalities, townships, and many states have already instituted some form of e-government. These sites offer a variety of online services ranging from the posting of town council meeting minutes to providing forums for discussion with public officials online in real time. ${ }^{20}$ As of 1997, there were 205 U.S. government agencies, 2,500 state governments, and 40 percent of all municipalities nationwide with a presence online. ${ }^{21}$ This trend is apparent worldwide and, based on recent estimates, continues to grow. In a survey conducted by The Economist and Andersen Consulting, 94 percent of the seven hundred se- nior civil servants surveyed believed advanced information technology will be an important driver of government change by 2010. More striking, however, was the fact that only 55 percent believed that IT was an important driver of change today.

The reason the respondents gave for this disparity is that as citizens grow to expect better services from government, they will be "more accustomed to the enhanced commercial services that the Internet and other Information Technologies make possible [by the year 2010]."22 This trend toward increased outsourcing has the most impact on the development of web related activities, such as e-government. In another national survey, Deloitte Research found that state government leaders project that "the number of citizens using the Internet as their primary means of access to government services will grow by 150 percent over the next two years," ${ }^{23}$ with the "largest increases for agencies that have the most direct contact with the public: 380 percent for state motor vehicle agencies and 228 percent for state revenue and taxation agencies." 24 Although managers are quick to recognize the importance of the Internet, there is also a realization that many public organizations are incapable of independently implementing the changes citizens are looking for, at least in the short term. The response to this trend has been a greater reliance on outsourcing, especially where e-government is concerned.

Janet Caldow of the IBM Institute for Electronic Government claims that defining e-government is not a simple task..$^{25}$ All too often, there is a tendency to oversimplify egovernment to just online procurement and dissemination of services and information previously only available either in person or by mail. In trying to formulate an e-government vision for their organization, public administrators must sort through the various claims and assertions to determine the viability of available options and implementation strategies. At Our Town 2000 (www.govt.com/ ci.desplaines.il.us), a privately operated website administered by Austin Professional Systems, residents of Des Plaines, Illinois can post requests for services ranging from tree trimming to street and sewer repairs. According to system administrators, "work requests are automatically routed to the proper division so the progress and completion of the work can be monitored." 26

At govWorks.com, also a privately operated site, users can access a "local government communication forum, which allows citizens to express their views on topics related to municipal government." ${ }^{27}$ City officials and local candidates for elections also have the ability to participate as 
"online guests," communicating with users through live "chat rooms," or by exchanging e-mails relating to a specific topic. Users of the site also have access to a nationwide directory of contact information for city and county offices, government agencies, and state offices. In addition to these features, govWorks.com also offers the ability for more conventional online services such as online channels for procurement and bidding. According to the information posted at the website, govProcure (online feature) provides information on local government Requests for Proposals (RFPs) and Requests for Bids (RFBs), including application and bidding processes. By offering a national market in which to advertise its procurement needs, govProcure helps enable the broadest participation of vendors in local government RFPs/RFBs. ${ }^{28}$

Isaza Tuzman, Chief Executive Officer and co-founder of govWorks.com, expects that as the site gains experience and additional exposure, the range of services will increase. She says that while they have established a core base of applications with complete functionality that operate on a nationwide basis, with or without government endorsement, a collaborative approach with local government would enable gorWorks.com to help them better serve their constituents with a richer and fuller set of services. ${ }^{29}$

The key to the success of both of these Internet sites, then, is the level of cooperation and collaboration with the local governments involved. Without access to information on how a public organization executes the delivery of its services, what services they provide, and in what areas, Internet sites offering to coordinate the provision of these services through e-government are disadvantaged. Yet more importantly, as more companies offer similar services through the Internet, administrators must gauge the impact on the organization's ability to remain responsive to both elected officials and constiruent needs. It must be remembered that although private companies may provide what can otherwise be regarded as a public service, they are not accountable in the same way as governments are when systems fail or requests remain unfulfilled.

Another consideration is if private firms continue to dominate the Internet in the provision of e-government services, administrators must be able to gauge whether this will discourage smaller governments from offering comparable services. The incentive to contract out or outsource will be strong, especially in light of the potential for significant cost savings. But administrators must take into consideration that, through outsourcing, organizations will lose the advantages that information systems bring, such as quick in- formation flow and direct lines of communication with service recipients. In addition, if organizations are to provide information, administrators must ask to what extent the quality and timeliness of the information disseminated is compromised through the outsourced relationship.

If the public sector is to harness the potential these systems provide, they must strive to offer these systems through their own resources and personnel. The role of public administrators is therefore to ensure that the capacities required to build and maintain these systems are available within an agency. At a minimum, they must carefully monitor the extent to which these services are outsourced, being mindful of where public interest and entrepreneurialism intersect and conflict. In order to manage these issues, administrators must not only be aware of, but must be willing to embrace, the future trend for more reliance on information technology in the public sector.

\section{The Management of E-Government}

Public administrators have a clear stake in helping to determine how electronic government will unfold at the most basic level. As the technology involved in enabling governments to offer automated services online or through other electronic means becomes increasingly available and affordable, administrators should question the now conventional practice of outsourcing and deferring implementation and design decisions to outside consultants. Instead, administrators must find ways to facilitate the growth and development of electronic government that develop internal capacities and embrace advancements in technology. This is necessary not only for the ongoing management of current information systems problems, but also to prepare public sector organizations to proactively manage future technology issues in a cost efficient manner. Without a proper base of knowledge as to how a particular technology will fit into an organization or benefit the public interest, what would prevent organizations from implementing the latest high technology advancement merely to keep pace with perceived expectations of how government should function? Therefore, when implementing technology changes, administrators must constantly evaluate these issues from both a technological and a public interest perspective.

A key area where public administrators can aid in the development of e-government is through the resolution of online security and privacy concerns and in communicating a broad-based understanding of the potential impact of e-government on the individual citizen. By facilitating clear industry standards that promote the growth of online services, 
public administrators can add lasting value to both the public and the private sectors. According to Von Hoffman of CIO Enterprise Magazine:

While the transformation of how government operates promises the most direct benefits for business, it is the transformation of governance-reexamining what a global, networked economy will mean to how democratic institutions work, to the relationship between the citizen and the state, and to the future of the nation-state itself-that seems to hold the most interest for both public and private sector participants in the project. ${ }^{30}$

It is obvious that there is tremendous value when governments are able to share and disseminate information concerning new activities or programs, especially in areas or with segments of the population not normally benefiting from this type of information. Concerns arise, however, when this information flow is reversed and information gathered by public organizarions about their constituencies falls into inappropriate hands, in particular when information pertaining to the personal habits or preferences of citizens is used for commercial gain.

This problem arose when Texas made driver's license and automobile registration information available to the general public. When a private firm developed a searchable website that included this information, anyone possessing "a Texas driver's license, a personal computer, and access to the Internet could then look up any other Texan and any Texan's license plate number." 31 What would impede the sale of electronic databases containing the social security numbers and birth dates of a state's population to commercial websites? Public administrators must be cognizant of this problem. As policymakers debate what to publish on the Internet, public administrators must take the lead in guiding the development of policies that both collect and disseminate information in secure and ethical ways.

Recent denial-of-service attacks on popular websites have highlighted the need for improved security standards in both the private and public sector. Many experts claim that this is an area where the privare sector must step in to ensure safery standards, yet there are others who place the burden of responsibility on the federal government. The federal government's inability to come to a consensus on how to protect its own infrastructure and recommend industry wide standards remains hindered by political inertia. The real problem, insists Roberta Gross, Inspector General at NASA, is addressing the "I don't care" culture within the federal government that "permits very simple and avoidable vulnerabilities to occur and reoccur [which] are no longer acceptable." 32 Senator Fred Thompson (R-Tennessee) recently said "it makes you wonder what in the world it takes to get the attention of federal managers." ${ }^{33}$ In a bill introduced last year by Senators Thompson and Joseph Lieberman (R-Pennsylvania), agencies would be required to "implement a security plan subject to annual independent audits; report unauthorized intrusions; and provide security awareness training for all its workers." ${ }^{34}$ Although many argue that this legislation would help clarify agency responsibility with regard to Internet security, it does not address the larger issue of complacency.

Public administrators, as agents of change, can aid this security process by coordinating training initiatives and facilitating an understanding of how technology will impact an organization. Particularly, in the public sector, employees must come to the realization that the use of complex information systems will become vital to the daily operation of any given public organization. Therefore, it is up to the administrator to manage the interpersonal and organizational changes that occur in organizations after new technology implementation, ensuring effective technology usage while remaining responsive to citizen demands for greater openness and efficiency. As Bingi, Sharma, and Godla write:

It is often said that new technology implementation is about people, not processes or technology. An organization goes through a major transformation, and the management of the change must be carefully planned (from a strategic viewpoint) and meticulously implemented..$^{35}$

The public administration profession must realize that in order to keep their organizations vital, administrators must take the lead in public organizations by proactively facilitating the implementation of novel information systems and developing in-house expertise that does not depend on outsourcing or on isolated agency IT departments.

\section{Conclusion}

Public administrators will have to assume more responsibility in facilitating necessary organizational changes when implementing new technology. As more organizations are discovering, successful implementation of enterprise integrating software requires a detailed perspective of the organization and a unique understanding of how the organization interfaces with the outside world. For the public sec- 
tor, not only must administrators and managers understand how the components of the organization relate to each other, but also must be able to accurately communicate how the organization effectively fulfills requests and delivers services. In the Information Age, public administrators must prepare themselves to interact with citizens through websites and e-mail. They will also be called upon to design and maintain online services and databases and act as integrators, facilitating the blend of organizational and constituency knowledge with new technology and capabilities sought therein. Public administrators must also remain cognizant of how new software innovations will affect the form and practice of administration. Of the many changes that must be monitored, it is the relationship between the public and the serviceproviding agency that will be affected the most. By maintaining a fluid dialogue that is unbound by time or geographic constraints, public administrators will be in constant, unfiltered contact with the public through technology. They will be better equipped to perceive and interpret the public interest and make administrative choices accordingly.

Yet whatever arrangements are made with regard to initial implementation and the degree of outsourcing, public administrators must develop sensitivities to the ongoing demands of IT management and how long term technology trends will impact mission functions. Public administrators need to encourage and nurture the development of inhouse technical competencies in order to keep pace with technological advancements. Public sector organizations should not always look to outside arrangements to shape the look and feel of government service delivery nor how it interacts with the public in an online society. As the costs for acquiring enterprise integrating systems fall, and the skills needed to maintain and operate these systems become more widely available, public administrators must act to facilitate the needed skill adaptation in existing personnel, as well as do more to attract the technically minded to public service.

Public administrators are now presented with the opportunity to revitalize their role in the new universe of e-government by helping to define and guide the public interest in a globalized, interconnected era. As the public sector moves to integrate its operations and investigate better means of interacting with the citizenry, public administrators will be charged with the tasks of both facilitating and implementing the changes, as well as being intimately involved in the continuing design and development of these new technologies. Even though the transition to integration or online service provision will not be easy for most organizations, the prospects for restoring faith in government, raising achievement measures, reducing costs, speeding delivery programs, and delivering services more efficiently are large incentives for embracing these new technologies. For many public administrators, this means a greater willingness to change their perceptions of their role in the organization and prepare to assume new roles and responsibilities. The successful transition and implementation of new technologies will depend on this change and on the management of organization-wide changes of not simply technology, but culture as well. It is here that public administrators must deploy their institutional knowledge and act as the hub for implementation strategies whose success relies on the careful management of people, as well as technology.

\section{Notes} 'Rowan Miranda, "The Rise of ERP Technology in the Public Sector,"
Government Finance Review (August 1999): 9.

${ }^{2}$ Ibid, 10.

${ }^{3}$ Bloomberg News, Deloitte \& Touche, PeopleSoft sued over softuare installation. 3 December 1999 hhttp://news,cnet.com/mews/0-1008-2-2$1402670 . \mathrm{html}$.

${ }^{4}$ Stephen J. Ventura, "The Use of Geographic Information Systems in Local Government." Public Administration Review 55 (September/October 1995): 461.

${ }^{5}$ Ibid, 464.

"Ibid.

${ }^{7}$ Ibid.

${ }^{8}$ Bloomberg News.

'Kim Girard and Melanie A. Farmer, "Business sofware firms sued over implementation" CNETNews,com, shttp://news.cnet.com/news/0-1008202-1428800.html>.

10 William Cats-Baril and Ronald Thompson, "Managing Information Technology Projects in the Public Sector," Public Administration Review 55 (November/December, 1995): 565.

"Prasad Bingi, Maneesh K. Sharma, and Jayanth K. Godla, "Cricical Issues Affecting an ERP Implementation," Information Systems Management (Summer 1999): 13.

${ }^{12}$ Mary M. Brown and Jeffrey L. Brudney, "A Smarrer, Better, Faster, and Cheaper Government: Contracting and Geographic Information Systems," Public Administration Review 58 (July/August, 1998): 335.

${ }^{13}$ Milford Sprecher, "The Future of ERP in the Pubtic Sector," Government Finance Review (August 1999): 49.

${ }^{14}$ Brown and Brudney, 337. 
${ }^{15}$ Steven Globerman and Aidan R. Vining, "A Framework for Evaluating the Government Contracring-Out Decision with and Application to Information Technology." Public Administration Revieu 56 (November/ December 1996): 580 .

${ }^{16}$ Nancy Ferris, "Outsourcing: Handwriting's on the Wall." GovExec.com, August 1999, shttp://www.govexec.com/rech/articles/ 0899 mantech,htm>.

17 Brown and Brudney, 334.

${ }^{18}$ Cats-Baril and Thompson, 564.

${ }^{10}$ Denis Saint-Martin, "The New Managerialism and the Policy Influence of Consultants in Government: An Historical-Insciturional Analysis of Bricain, Canada and France," Governance: An International Journal of Policy and Administration 11 (July, 1998): 334.

${ }^{20}$ Kevin Gallagher, "Betrer customer service stems from increased efficiency due to automation" APWA Reporter, <http://e-government.org/ apwa2.hrm>; Govworks.com, "Govworks.com Brings Interner Revolution to Local Government." 20 September 1999, <http:// www.gowworks.net/news_articles/sept20 htmls.

${ }^{21}$ Donald C. Menzel, "www.ethics.gov: Issues and Challenges Facing Public Managers," Public Administration Review 58 (September/October, 1998): 446.

22 Ferris.

23. Deloitte \& Touche, "At the Dawn of E-Government: The Citizen as Customer," <http://www.dc.com/deloitte_research/featured/e-govt/ index.asp>.

${ }^{24}$ Ibid.

25 Janer Caldow, "The Quest for Electronic Government: A Defining Vision." Institute for Electronic Government, <http://www.ieg.ibm.com>. Defining e-government is difficult because the term is still relatively new. Some would argue that the term refers to electronic commerce while others use it to refer to online procurement. In addition, a narrow definition may exclude some inherent qualities of what constitutes e-government while a broad definition might dilute its meaning, weakening the emerging movement supporting e-government.

${ }^{26}$ Wilma Randle, "Ciry Offers Public Works Aid on the Inrerner." Chicago Tribune. December 1999 <http://e-government.org/story.htm>.

${ }^{27}$ Govworks.com.

${ }^{28}$ Ibid.

"Ibid.

${ }^{30}$ Constantine Von Hoffman, "The Making of E-Government." CIO Magazine, November 1999, <http:/www.cio.com/archive/enterprise/ 111599_egov_content.html>.

"Mi Menzel, 447.

32 Nancy Ferris, "Senator: No laws can fix careless computer security. GovExec.com (Government Executive, 3 March 1999, <htcp:// govexec.com/dailyfed/0300/030300nl.htm>.

3. Ibid.

${ }^{34}$ Ibid.

${ }^{35}$ Bingi, Sharma, and Godla, 13.

\section{Bibliography}

Bingi, Prasad, Sharma, Maneesh K., and Godla, Jayanth K., "Critical Issues Affecting an ERP Implementation." Information Systems Management (Summer 1999): 7-14.

Bloomberg News "Deloitte \& Touche, PeopleSoft sued over software installation". 3 December 1999 <http://news.cnet.com/mews/0-1008-2-21402670.html>.

Brown, Mary M., Brudney, Jeffrey L., "A Smarter, Better, Faster, and Cheaper Government: Contracting and Geographic Information Systems." Public Administration Review 58 (July/August 1998): 335-345.

Caldow, Janer, "The Quest for Electronic Government: A Defining Vision." Institute for Electronic Government (1998)<http:// www.ieg.ibm.com>.

Cats-Baril, William, and Thompson, Ronald, "Managing Information Technology Projects in the Public Sector." Public Administration Review 55 (November/December 1995): 559-566.

Deloitte \& Touche "At the Dawn of E-Government: The Citizen as Customer," <htrp:/www.dc.com/deloitte_research/featured/e-govt/ index.asp>.

Ferris, Nancy "Outsourcing: Handwriting's on the Wall." GovExec.com (Government Executive), August 1999 <http:/www.govexec.com/ tech/articles/0899mantech,htm>.

Ferris, Nancy, "Senator: No laws can fix careless computer security." GovExec.com (Government Executive), 3 March 1999, <http:// www.govexec.com/dailyfed/0300/030300n1.htm>.

Gallagher, Kevin, "Better Customer service stems from increased efficiency due to automation." APWA Reporter, (1999) <http://egovernment.org/apaw 2 .hem>.

Girard, Kim, and Farmer, Melanie, A., "Business software firms sued over implementation." CNET News.com, 3 December $1999<$ htcp:// news.cnet.com/news/0-1008-202-1428800.html>.

Globerman, Steven, and Vining, Aidan R., "A Framework for Evaluating the Government Contracting-Out Decision with and Applicarion to Information Technology." Public Administration Review 56 (November/December 1996): 577-586.

Govworks.com Brings Internet Revolution to Local Government." Govworks.com, 20 September 1999 <http://www.govworks.net/ news_articles/sept20.html>. 
Menzel, Donald C., "www.ethics.gov: Issues and Challenges Facing Public Managers." Public Administration Review 58 (Septemberl October 1998): 445-452.

Miranda, Rowan, "The Rise of ERP Technology in the Public Sector," Government Finance Review (August 1999): 9-17.

Randle, Wilma, "City Offers Public Works Aid on the Internet." Chicago Tribune. (December 1999) <http://e-government.org/story.htm>.

Saint-Martin, Denis, "The New Managerialism and the Policy Influence of Consultant in Government: An Historical-Institutional Analysis of Britain, Canada and France." Governance: An International Journal of Policy and Administration 11 (July 1998): 319-338.

Sprecher, Milford, "The Future of ERP in the Public Sector." Government Finance Review (August 1999): 49-50.

Ventura, Stephen J., "The Use of Geographic Information Systems in Local Government." Public Administration Review 55 (September/ October 1995): 461-467.

Von Hoffman, Constantine, "The Making of E-Government." ClO Magazine, 15 November 1999 <http://www.cio.com/archive/enterprise/ 111599_egov_content.html>. 
